\author{
Marquette University \\ e-Publications@Marquette
}

\title{
Rhetorical Body Work: Professional Embodiment in Health Provider Education and the Technical Writing Classroom
}

Lillian Campbell

Marquette University, lillian.campbell@marquette.edu

Follow this and additional works at: https://epublications.marquette.edu/english_fac

Part of the English Language and Literature Commons

\section{Recommended Citation}

Campbell, Lillian, "Rhetorical Body Work: Professional Embodiment in Health Provider Education and the Technical Writing Classroom" (2021). English Faculty Research and Publications. 562.

https://epublications.marquette.edu/english_fac/562 


\section{Rhetorical Body Work:}

\section{Professional Embodiment in Health Provider Education and the Technical Writing Classroom}

Lillian Campbell, Marquette University, lillian.campbell@marquette.edu

This article introduces "rhetorical body work" as a framework for understanding professional embodiment in health provider education and technical writing pedagogy. Using the case study of clinical nursing simulations and drawing on sociological theory, I provide a detailed analysis of three components of rhetorical body work as they manifest in three simulation scenarios - physical, emotional, and discursive. I conclude by considering the implications of these findings for the embodied teaching of technical writing.

Keywords: rhetoric of health and medicine; nursing; rhetorical theory; pedagogy; multimodal communication 


\section{Rhetorical Body Work: \\ Professional Embodiment in Health Provider Education and the Technical Writing Classroom}

As the population ages and life expectancy increases in the United States, demand for health care providers is rising ("Health Care Employment," 2018). And even as health care moves into virtual spaces, a provider's embodied interactions are still central to how they know their patients (AUTHOR, 2019). The field of rhetoric of health and medicine can contribute to this changing landscape by attending to the writing experiences of health care practitioners on the job (Opel \& Hart-Davidson, 2019) and in educational spaces (AUTHOR, 2018). At the same time, our field has much to learn about pedagogical practices that center embodiment and responsive communication from these professional training contexts.

Health provider education must teach physical regulation of the provider's body, physical engagement with the patient's body, and emotional management of self and other, alongside practice in how to write and speak. Consider one junior year nursing student's description of a nurse's role during an interview:

[Nurses] would get labs back that were critical [...] and in front of the parents they would be serious and say, 'This isn't necessarily the sign that we're looking for' $[\ldots]$ and then the door closes and they're running trying to find someone else because whatever they saw is a big deal and that isn't okay.

This description emphasizes a wide range of embodied action — from emotional modulation in front of the parents to running down the hall. However, the description is also clearly rhetorical, demonstrating a flexible awareness of how actions change "depending on who you're talking to," as the student explained, and encompassing professional texts (interpreting labs), verbal communication, and physical interaction. 
This article introduces "rhetorical body work" as a theoretical framework for understanding experiential health provider education. The sociological concept of body work describes "the labor performed on other's bodies [...], emotional labor, and the effects of work on one's own body" (Fisher 2009, p. 2669). After overviewing sociological research and demonstrating how rhetorical theories can add a focus on interactive persuasion to this framework, I analyze three components of rhetorical body work: physical body work, emotional body work, and discursive body work. I draw on indicative examples taken from a larger ethnographic study conducted on clinical nursing simulations - structured classroom scenarios where students practice care on a robotic patient - to consider the following research questions:

(1) How do students learn to move like a nurse through physical interactions with the people, objects, and environment of the simulation labs?

(2) How do students learn to modulate their own emotions and the emotions of their patients, especially when negotiating difference?

(3) How do students discursively capture their body work and prompt future body work from other providers through their communication and documentation?

Thus, my findings speak to health care pedagogy and the rhetoric of health and medicine by offering examples from clinical simulations that demonstrate how body work is deeply rhetorical—centered around communication and persuasion—and not easily separated from students' discursive experiences within the field. I then conclude by considering the implications of these findings for the embodied teaching of technical writing. When we ask students to take on a variety of perspectives and speak to a range of audiences in technical communication classrooms, rhetorical body work calls attention to the complex, embodied work that is embedded in such tasks. 


\section{Literature Review}

\section{Origins of Body Work}

Body work can be broadly defined as "paid work that takes the body as its immediate site of labour, involving intimate, messy contact with the $[\ldots]$ body, its orifices or products through touch or close proximity" (Wolkowitz, 2006, p. 8). Thus, body work exists at an intersection between consumer markets and physiological experiences including touch, smell, and sight. Both Wolkowitz (2002) and Gimlin (2007) argue that Sociology tends to overlook this nexus between work and the body. Wolkowitz (2002) has called for contextualizing the body's formation as part of "routinized workplace encounters, mediated by the cash nexus, and located within wider social inequalities" (p. 505). She argues that particularly in blue-collar jobs, which have transitioned from the factory assembly line to customer-facing positions, workers' bodies are in constant physical and emotional interaction with others.

In her review of contemporary body work research, Gimlin (2007) argues that sociologists have taken four approaches: body/appearance work; body work/labor; body/emotion management; and body making at work (p. 355). Given my project's focus on the workplace and connection to paid labor, the last three approaches hold the most relevance for an analysis of nursing students' experiences. Wolkowitz's book (2006) focuses on body work/labor by considering how the circulation of body work reinforces class stratification along racial and gender lines. For example, female immigrants often take on the most bodily tasks as nursing assistants or nail technicians. Similarly, Hochschild's (1983) research on emotional management considers how employees produce or suppress emotions, like the demand that waitresses be smiling in front of customers. The fourth category - body making - attends to how work acts back on the bodies and emotions of the employee creating lasting effects. For example, the 
stress of working as a nurse might take a toll on a worker's blood pressure, while being on their feet all day might strain a prior ankle injury.

While writing studies scholars have recently focused on questions related to both student's work experiences (e.g. Brittenham, 2017; Lu \& Horner, 2009) and embodied knowledge (e.g. Knoblach, 2012; LeMesurier, 2016), similar to Sociology our attention to the body/work nexus has been limited. Elizabeth Britt's (2018) recent book on how law students learn embodied strategies for advocacy in a legal clinic and T. Kenny Fountain's (2014) exploration of biology student's acquiring professional discourse through cadaver dissection are two notable exceptions. Meanwhile, the field of human factors and ergonomics in technical communication has long held an interest in studying intersections between work and "human anatomical, anthropometric, physiological, and biomechanical characteristics" (Karwowski, 2012, p. 4). However, this field prioritizes human-artifact interaction in workplaces, thus physical interactions between worker and client bodies as well as the social distribution of power are less central to this approach.

Overall, by bringing the lens of body work to rhetorical studies, this project provides a framework for future projects that investigate the relationships between students' embodied experiences in the classroom and their discursive disciplinary training. At the same time, a rhetorical approach to body work emphasizes its interactive and persuasive nature in ways that have been over-looked in sociological scholarship, including how bodily exchanges between practitioner and patient are discursively captured and communicated to others.

\section{Body Work and Gendered Labor}

Research on body work is always inextricably linked to questions about gender, race, and the distribution of power across bodies. Sociological theories of body work emphasize how it is devalued within social and institutional systems and frequently 
gendered as "women's work." In health care contexts, prestige is often established by limiting physical contact with the patient body or cordoning it off into neat "parts" and those with the lowest standing, like immigrant women, perform the dirtiest jobs.

Rhetorical scholarship has recently been calling for more attentiveness to gender as it intersects with professional discourse as well. The recent book Women \& Work argues that there has been an over-emphasis in feminist scholarship on women's civic participation, which can also lead to a focus on white, upper-middle-class women (Gold \& Enoch, 2019). Hallenbeck and Smith (2015) suggest, “"work' has been both everpresent in [feminist rhetorical] scholarship and simultaneously, somewhat tacit, invisible - under-theorized as a discrete area of study" (p. 201). Similarly, Frost (2017) has introduced a methodology of "apparent feminism, which argues masculinist values like efficiency in contemporary workplace contexts are often tacit and seen as natural, necessitating a critical feminist approach.

Despite their interests in the workplace, both sociologists and rhetorical scholars have recognized that educational spaces are productive sites for studying the intersections between gender, bodies, and work. As Hallenbeck and Smith (2015) argue, "Sites of education are powerful loci within which students develop an intellectual and physical habitus, and thus often serve to naturalize gendered, classed, and raced relations" (p. 214). Along these lines, sociologist Emma Wainwright et al. (2010) researched body work in the British "classroom-salon," where mothers receive training in massage therapy. Wainwright et al. show how paradoxically, while instructors emphasize the women's "natural" predilection for the work as an extension of their maternal identity, they also encourage students to tone down their femininity to highlight scientific expertise (p. 84). 
Other authors have argued that when individuals leverage embodied knowledge this can offer a powerful counter-discourse to dominant masculine ideologies. As Knoblach (2012) argues, “an embodied rhetoric born from embodied knowledge [...] can rattle loose the privileged white masculinist discourse" (p. 62). In a recent chapter about clinical simulations (AUTHOR, 2020), I show how both overt and implicit lessons teach nursing students how to perform their gender. At times, these lessons resist a hospital culture of objectivity and distance and position the nurse as an advocate for the whole patient's embodied experiences. This chapter builds on that research and other scholarship on body work, gender, and nursing (Fisher, 2009) to consider how gendered performances intersect with physical and emotional maintenance in the education of healthcare professionals.

\section{Body Work in Medical Contexts}

While sociological research on body work has explored contexts ranging from massage therapy (Wainwright et al., 2010) to prostitution (Wolkowitz, 2006), workers in medical contexts have received only limited attention. The most in-depth exploration is a 2011 special issue on body work in "Health and Social Care." Particularly relevant is Brown et al.'s attention to gynecologists' use of speech acts and physical acts in establishing patient trust and Harris' (2011) interest in habitual action and the importance of disruption in facilitating learning. However, these authors focus on physician or patient experience, overlooking a myriad of other practitioners.

Nurses, of course, are some of the most physically interactive health care providers; touch and emotional interactions with patients are at the heart of their practice. Still, research on the body work of nurses specifically has rarely used a sociological framework or attended to nurses rather than patients - for exceptions see Shakespeare (2003) and van Dongen and Elem (2001). Another exception is Fisher's 
article, which draws on interviews with Australian male nurses to describe the physical and emotional strategies they use to downplay their gender in a feminized profession.

Of course, interviews have limitations for the study of body work, since movements are often tacit and habitual (Harris, 2011). Thus, by using body work as a theoretical frame and drawing on observations of nursing students alongside interviews and document collection, this project can offer unique insights into both the theory of body work and nurses' learning experiences.

Scholarship in the rhetoric of health and medicine has recently been integrating field work and ethnographic studies of writing and scientific practice are on the rise. Fountain's Rhetoric of the Flesh (2014) draws on ethnographic research in a gross anatomy lab where students learn through cadaver dissection. He develops a theory of trained vision that accounts for its integration in a professional community of practice:

We develop trained vision through our rhetorical and embodied engagements with the objects, displays, discourses, and documents that constitute that domain of practice. This trained vision plays a crucial role in structuring and generating our thoughts, perceptions, and possibilities for action, and it does so by shaping the ways our bodies respond to our environment. p. 194

Fountain's theory resonates well with prior research on physical body work, especially through its emphasis on how body work is acquired at the intersection of objects, people, and places. However, the gross anatomy lab offers fewer opportunities for reflection on emotional and discursive student learning. Considering how students learn to have conversations with patients - and negotiate their own emotional maintenance and the emotions of the patient—is outside the scope of his study. Similarly, the power dynamics of the clinical exchange are less visible within Fountain's research. This limited attention to power differentials is, in fact, a common critique of research on embodiment. Recent feminist philosophers have critiqued materialist approaches to 
scientific rhetoric - especially those relying on object-oriented philosophy - for eliding power relationships between human participants (Booher \& Jung, 2018). Thus, in addition to offering a view of sociological body work that is attentive to its interactive and persuasive nature, rhetorical body work also offers a rhetorical theory of embodiment that accounts for the distribution of power across both worker and client bodies and the body's role in negotiating difference.

\section{Methods}

Northwest University’s Clinical Performance Lab (CPL) occupies 20,000 square feet on the fourth floor of an urban medical center and is used by undergraduate and graduate nursing students. While the CPL includes low-tech and mid-tech manikins to practice basic assessment and skills, its focal point is two simulation suites with technologically advanced robotic patients - Joe/ Josie in the adult suite and Hal in the OB/pediatric suite (see Figure 1). These patient manikins can breathe, blink, and even go into cardiac arrest - all controlled by the simulation coordinator who sits in a control room with onesided windows. Most importantly, the manikins "speak" through a microphone in their mouths also connected to the coordinator. The simulation coordinator in this study was Maura and her full-time job was designing and organizing materials for the simulations, orienting students to the process, and running all simulations.

\section{INSERT FIGURE 1 HERE}

In addition to the manikins, the simulation room is stocked with supplies gloves, oxygen, catheters, blood drawn IV's, etc. There is also a computer in each room, so students can look up any medication, and a phone that connects to the control room. Students verbalize who they are calling and an instructor fields the call. The "medication room" is a cart on the other side of the room and there is also a large white board that students use to collaboratively chart the patient's health information. 
Undergraduate nursing students begin practicing full simulation scenarios with the high-tech patient manikins at the beginning of their junior year, after learning skills like catheter insertion on low-tech manikins. During simulation scenarios, students are immersed in a particular narrative set up by the coordinator that provides them with an opportunity to take on the roles of nurses providing care. In the simulations I observed, three groups of 2-3 students each took turns caring for the patient for approximately twenty minutes, while the patient's condition worsened. During their turn, students practiced conversations with one another and with the patient, identified possible causes of complications, and decided on interventions. They also had physical interactions with the simulation environment and the manikin-applying sanitizer, putting on latex gloves, adjusting the patient's dressing gown, checking wounds, etc. While one group provided care, the other two sat in a nearby classroom watching a video stream of the simulation. After each group's turn, the students, clinical instructor, and simulation coordinator reconvened in the classroom to debrief their experience. Here, they discussed what went well and what they might do differently, with students from the observing group assigned to provide specific feedback on topics like communication and technique.

Data collection included observations and video recording of three simulation sequences by all groups (30 simulations and 90 hours in total) over the course of the 2014-15 academic year; observations and field notes on debrief conversations; interviews with instructors and five focal students who indicated interest in study participation during recruitment; and collection of focal student writing and documents that circulated in the simulation space. This research was exempted by the Human Subjects Review Board at my institution and the institution where it took place. I use pseudonyms throughout this article to protect participant anonymity. 
My initial coding scheme for field notes and interviews was based on theories of genre and their emphasis on the intertextual, social, and embodied nature of communication (see AUTHOR, 2017). I open-coded my materials according to the following scheme:

1) Writing or engagement with written texts influenced action ("write");

2) Verbal communication between student and patient, multiple students, or student and another provider influenced action (“comm”)

3) Physical encounters with the patient or environment influenced action ("material")

In order to apply the framework of rhetorical body work for this project, I returned to my coding with an eye towards physical, emotional, and discursive management. Specifically, I honed in on moments where physical encounters overlapped with written and communicative encounters. This helped me to narrow down my corpus of examples and to identify situations that exemplified the three components of rhetorical body work. Choosing excerpts that exemplify the three components is in line with my research questions for this article, which aim to understand how they manifest in health provider training but not to account for every instantiation.

\section{Findings}

In this section, I focus on one example of each of the three components of rhetorical body work - physical, emotional, and discursive. In doing so, I consider both what students are learning about the ways nurses move and interact in the world, how the simulation supports this learning, and the limitations of learning embodied communication in a context that does not look or feel quite like the real world.

\section{Physical Body Work: "Hands On, Ears On, Eyes On the Patient"}


During their orientation to the simulation room, coordinator Maura reminds students that even though the patient's vital signs are visible on a telemetry machine, they should not rely on this information. Instead, she emphasizes that "just like in clinicals, you should have hands on, ears on, eyes on the patient at all times." What this means in practice is that the simulator, specifically, and the simulation environment, more broadly, have an active rhetorical role in the simulation and that they persuade in a range of physical, visual, and auditory ways. Like Fountain (2014) demonstrates in his analysis of cadaver dissection, physical body work is shaped by both human participants and interactions with persuasive objects.

In the following excerpt from the second round of simulations, student nurses Sean and Stephanie make up the third shift caring for Jason Lee, a 22 year-old patient who has just had surgery in both femurs after a car accident. The students are anticipating that the blood clot the previous shift located in Jason's left calf is going to move to his lungs. However, Maura has decided to add a last minute allergic reaction to a medication. The following conversation unfolds as Sean and Stephanie physically negotiate Jason's care and the reaction.

Sean: [Rubbing anti-bacterial gel on his hands] We're going to try and get that taken care of for you right away. I understand what it feels like to be itchy. Jason: It's really annoying it's just...

Sean: And you said it's all over, no particular area? Not maybe just your leg? [Pulls latex gloves from the box near the head of the bed and comes to Jason's right side.]

Jason: No I mean I just feel that it's like my stomach and my neck.

Sean: [Putting on latex gloves.] Alright, I'll hold off on the folie [catheter] and I can take a look at your skin. Can you describe the itch a little bit more to me? Is it just... you said it was annoying, is it painful or anything?

Jason: No it's just literally itchy.

Sean: [Uses both hands to feel neck] Itchy around your neck? And your stomach you said? Do you mind if I take a look? 
Jason: Almost kind of everywhere. Sure.

Sean: [Folds down the blanket on Jason's torso] I'm going to expose your stomach here. [Lifts up the patient's dressing gown. Touches the top part of Jason's chest lightly with his right hand while he holds the dressing gown up with his left $]$ There is a little bit of... would you say its bruising?

Stephanie: [Walks from the medicine cart to Sean's side] That's from the accident. Jason: Yeah it's a little tender there. I have that seatbelt bruise.

Stephanie: [Comes behind Sean to check Jason's IV bags]

Sean: [Gently touches different spots around the torso] As I'm touching it, can you describe to me what you feel?

Jason: Well it just feels like a bruise, you know.

Sean: Sorry, your abdomen.

Jason: Ohhhh. Oh it's okay.

Sean: Its okay? Does the itching get relieved when I touch it?

Jason: Uh no not really. It doesn't make a difference.

Sean: [Turns to Stephanie who is walking towards the medicine cart and reaches over to grab medication.] What do we have for the...?

Stephanie: [Walks back towards the bed.] So I was reading that itching can be a side effect of the Lovenox [Walks back towards the medicine cart]

Sean: [Pulling Jason's gown down and blanket up over his torso.] And is um [Gestures to the medication Stephanie is holding] that can heighten the...

Stephanie: [Reading off the physician's orders at the medicine cart] Yeah, twentyfive milligrams IV push every six hours, yeah.

Sean: So Jason we've got, I don't know if you overheard our conversation.

Stephanie was talking about how itching could be a side effect of the Lovenox that the previous shift gave you.

In this excerpt, students move around the physical space of the simulation room, apply sanitizer, put on latex gloves, check physician's orders at the medicine cart, and adjust the patient's blankets. All of these movements provide opportunities to practice occupying a clinical space like a nurse. They also physically interact with the manikin, adjusting his dressing gown and touching his neck and chest, verbally narrating these actions when appropriate (see Figure 2). In this way, the simulation setting offers affordances for practicing the physical interactions of nursing. 


\section{INSERT FIGURE 2 HERE}

At the same time, the simulation environment enforces certain limitations on the nurse's body work. These can create what the group referred to as "simisms" - mistakes caused by the differing environment of the simulation. For example, students often forgot to switch to clean gloves after a procedure. In clinical contexts the presence of bodily fluids is more likely to prompt a change. Similarly, because the simulation all takes place in one room, the medication "room" is actually just a cart in the back of the room. Students are told to pretend that this is a separate space, but it is often hard to negotiate when the patient can or cannot overhear their conversations.

The manikin's body is similarly limited. While internal vital signs are controlled with the computer so Maura can easily adjust things like heart rate, breathing, and pupil dilation, the manikin's surface is more difficult to change. With preparation ahead of time, Maura can add things like the bruises and the blood clot, which she fabricated with a hand-sewn microwaveable rice pack. However, the spontaneous itching was not visible on Jason's skin. Sean mentioned in debrief his confusion with assessing the patient's skin when there were no visible symptoms.

Given the environmental limitations, the instructor is also critical in prompting students' physical experiences. Since I was sitting in the instructor room behind a oneway mirror with Maura, I observed the way that she would physically immerse herself in the patient's character. Sometimes she would enact patient experiences, scratching her neck, for example, while the patient complained of itching. During a sensitivity test where a student was poking the simulator's foot with a pen, Maura had to stand up and strain to try to see when the poke was being delivered and respond. Thus, links and disconnects between Maura's body and the simulator's body were an important part of the simulation's rhetorical context that prompted student action. Maura's rhetorical 
responsivity - her immersion in both the verbal action of the simulation and the physical exchange - was a critical part of teaching student lessons in body work.

Overall, simulations teach students to move like nurses using the manikin for physical interaction, the tools in the simulation room, and the simulation space. The simulation environment and the instructor's ministrations provide lessons in body work by prompting students to react to unexpected physical encounters and to experience the consequences of their physical interactions in immediate ways. At the same time, however, the simulation environment often creates imperfect bodily experiences that do not exactly mimic the clinical context. These imperfect physical encounters can be disruptive, but as Harris (2011) has argued, disruptions can be a valuable contributor to bodily learning since they destabilize habitual action and prompt reflection.

\section{Emotional Body Work: Performing and Internalizing Feelings}

Just as students learn to effectively move around the clinical space and interact with the patient, they also learn to perform appropriate emotions for the clinical workplace. Gimlin (2007), drawing on the work of Arlie Hoschschild (1983), describes this component of body work as emotional labor - "the management of feeling to create facial and bodily displays expected from employees" (p. 361). Emotional body work encompasses face-to-face and voice-to-voice contact with patients as well as producing particular patient emotions (i.e. keeping them calm) and regulating their own emotions (i.e. not displaying disgust). Brown et al.'s (2011) research finds that a patient's feelings of trust towards their provider draw on both verbal statements and physical actions, making it difficult to separate emotional and physical body work. Indeed, Wolkowitz (2002) warns against drawing too sharp a distinction between the two as reinforcing Cartesian mind-body dualisms (p. 499). 
Still, verbal and physical performances that are intended to elicit particular emotions in patients warrant further exploration. According to Hoschschild (1983), emotional labor can take the form of surface or deep acting. When surface acting, a worker performs emotions that they are not actually experiencing, like smiling even if they are unhappy. When deep acting, a worker consciously changes their emotional state to feel the emotion they are performing, like empathizing with a difficult patient by relying on stereotypes about that patient's demographic group. For example, Gimlin (2007) describes how a provider might "consciously reorder elderly people as sweet, innocent, and vulnerable [...] to overcome their feelings of disgust" (p. 362-3). In simulations, where instructors may not have the proper background to perform particular demographics, these issues are complicated further.

At the end of another group's simulation with Jason Lee, the blood clot from his legs has moved to his lungs and he is struggling to breath. "What should I do?" Jason gasps. One student in the simulation, Alice, had previously latched onto Jason's Chinese heritage, conversing about her experiences with Chinese culture. In fact, Alice put coordinator Maura's cultural knowledge to the test when she asked Jason about his favorite food for Chinese New Year. Luckily, a student intern happened to be in the observation room with Maura and suggested moon cakes. Now Alice says: “Think about... imagine that you're Buddha [...] Imagine - you know how he stayed underneath that tree for forty-nine days? Just imagine that just, channel your inner Buddha."

This was a strange and unique moment during my simulation observations. Despite the fact that two of the three simulation characters - Eliana and Jason - are ethnically marked in their patient profile images and their last names, I found that students largely ignored race during care. Similarly, Maura rarely leveraged opportunities to make race or ethnicity a point of conversation when she interacted with 
students in the patient role. She did much more to encourage students to address gender and age. Patients would make comments about being more comfortable talking to a nurse of the same gender about a catheter, for example (see AUTHOR 2020).

This exchange shows the challenges for a new nurse in navigating the difficult emotional terrain of patient panic as Jason's health rapidly deteriorates. In addition, it demonstrates how one nurse attempted to connect emotionally with a patient through shared cultural background. While it felt uncomfortable for observers because it seemed presumptuous to talk about religion without knowledge of Jason's background, Alice was actively immersed in the simulation and working to calm Jason down. She was both modulating her own emotional reaction to the stressful situation and also managing the patient's emotional state to the best of her ability. In an effort to push this emotional work further, the instructor prompted Alice to provide physical comfort as well by having Jason respond with, "Will you hold my hand?"

In the final moments of this simulation Jason was being transferred to the Intensive Care Unit and was still struggling to breathe. A bit of joking had already ensued with the respiratory therapist (the instructor) and Alice left Jason with the comment, "Imagine Buddha, but not too hard. Don't go to Buddha." Here, the facade of the simulation had been removed and the cultural reference that had served as a point of connection between patient and nurse became a source of humor about his death. The instructor laughed and touched Alice affectionately on the shoulder and it was clear that she and the students had removed themselves from the simulated moment.

In an interview, a student who had been the audience for this simulation, Kira, mentioned Alice's interactions when I asked if she remembered anything about other groups' communications with Jason. She responded, "Yes. Yes. Go to Buddha," indicating that this had been a memorable and problematic moment. Kira attributed the 
awkwardness to the simulation context: "I think they just got thrown off by the Sim and it just — it just went so bad." I did not press further, but Kira appeared to share in my experience of these comments as jarring and inappropriate. The joke's cultural insensitivity coupled with the dismissiveness about death made it an upsetting moment that seemed to undermine patient-nurse relations. Singer (2013) begins an article with a similarly troubling anecdote about a group of nursing students laughing after arranging a simulated body so that the top half is male and the bottom half is female. Singer argues, "The laughter of these students, if neither purposeful nor malicious, reveals that trans-specific embodiment is unthinkable, hence invisible, in clinical settings" (p. 250).

In contrast, one could argue that the capacity to find humor in the face of death is a necessary emotional skill for a future nurse, one that distances her from her patients, yes, but also enables her to continue to perform emotional body work. Hochschild (1983) warns about the detrimental effects of constantly suppressing emotions in workplace contexts. Meanwhile, reflecting on his experiences of joking during a townwide anthrax simulation, Magelssen (2014) argues that humor is productive in its capacity to strengthen participant relationships: "The laughter likely fostered the kind of goodwill and camaraderie that drove home for participants how much they valued their hometowns, families, and social networks" (p. 137). For Magelssen, flexibility and willingness to embrace moments that step outside of the simulation scenario can help support community building and camaraderie.

Thus, humor among students as they negotiate the boundaries between the real and the simulated might provide necessary emotional release and reinforce in-group identity for the burgeoning professionals. But this levity is troublesome when it reinforces stereotypes about non-normative body types or cultures, as in the two examples above, and disregards empathetic exchange. That is, humor becomes 
problematic when it overshadows the important learning about emotional modulation that is a focus of lessons in body work. These emotional lessons are further complicated by the distance between the facilitators in simulations and the demographics of the patients they represent. My initial observations suggest that there is more work to be done in leveraging nursing simulations to teach cultural responsiveness and attention to differences like race and class, alongside emotional performances like empathy.

\section{Discursive Body Work: Encoding Sensorial Encounters}

In their investigation of a primary care clinic, Opel and Hart-Davidson (2019) find that although it is devalued by practitioners, writing is of paramount importance: "the most valuable thing that primary care clinicians produce is $[\ldots]$ a record of the body that can assist in caring for that body over time" (p. 21-22). However, given that patient information is often gathered at an interface between patient and practitioner bodies, translating embodied knowledge into discursive documentation is not always straightforward. Mulla (2014) describes forensic nurses as producing evidentiary rape records "encod[ing] rich sensorial encounters [...] involving pain, odors, and bodily discourses" (p. 24). In a similar way, nursing students must learn to encode knowledge gained from bodily interactions into their patient's medical chart so that they can become part of a "record of the body."

While the focus of this section may seem distinct from previous sections because attention is on documenting the patient's body (i.e. skin condition), all of this information has been gathered through bodily interactions between nurse and patient described in previous sections (i.e. palpating the skin). Thus, the nurse's body work is at the heart of their patient knowledge, which is part of what makes it challenging to discursively translate that embodied knowledge for others. Overall, I argue that a 
rhetorical view of body work emphasizes its relationship to written discourse, which has received less attention in sociological research.

In clinical simulations, all patient documentation was done on a large white board in the center of the room. Prior to the start of the simulation, the full group of ten students would decide on a template for charting, including what categories to include and how to differentiate between each team's care. During one group's geriatric shift they struggled to prioritize some of the physician's orders in their care. However, as they stood at the board deciding on priorities for the next group, they were able to check in about knowledge gained through embodied encounters with the patient and to decide on next steps. Becky documented while the other group members stood next to her at the board (emphasis added):

Christian: Did you assess her vitals yet, after we administered the medication?

Mia: No I was only able to get her pain levels.

Christian: Okay we gotta, so for the next people, assess her blood pressure.

Becky: But we didn't get, oh for the next group we definitely need to have them do the dressing change or they...

Christian: Yeah, yeah so we gave the morphine but um also to assess her blood pressure and her respiratory as well because we gave her morphine and also her pain level once before they do the dressing change and the catherization.

Becky: So monitor for side effects from morphine?

Christian: Yeah, like really low blood pressure...

These students are negotiating priorities using not only the physician's orders but also their physical and verbal encounters with the patient throughout their simulation. They are able to account for the information that has been gathered through these patient encounters (i.e. pain levels) and the interventions that have been made in response (i.e. administering morphine). At the same time, they recognize the gaps in their care and the need for further patient information. Drawing on Becky's verbal interactions with the 
patient during which she admitted to dribbling on her dressing wound, they collaboratively prioritize dressing change and catheterization. On their board, this group's conversation is visible in the notes for the following group. In addition to charting their administration of the morphine, under interventions they noted, "premedicated for dressing" and bolded the note to "change." In "Additional Info" they indicated the group should "monitor for side effects from morphine" (see Figure 3).

\section{INSERT FIGURE 3 HERE}

Once the group has translated their body work into the patient medical chart, the chart becomes a primary object of reference in the hand-off to the following group. Both groups gather near the board, with the incoming nurses facing with their backs to the board, and the nurses who charted facing the board (emphasis added):

Becky: Oh yeah, so anyway she's post-op two weeks [...] As she came in this morning, she also hurt her left ankle. We ordered an x-ray for it because the doc wants us - she said that they did not evaluate in the ED and the doc wants us to wrap it. Just wanted to make sure nothing's broken.

Mia: Um we administered morphine about an hour ago and in about an hour or two if you guys want to do a catheritization because she is incontinent and we want to do a dressing change in a few hours, after - like an hour after that just so the incontinence doesn't leak into her wound while we are changing it.

Christian: Also we just want to assess her pain and um after we administered the morphine we didn't really check about like um the effects afterward so please check her blood pressure, for any respiratory depression, and just like you know like how conscious she is and stuff so yeah please check for that as well, make sure she's good...

Becky: And then her last set of vitals are on the board there so...

Mia: And she is also diabetic and she took her insulin this morning and she had a...

Michelle: Have you guys taken her blood sugar after that since she's been here?

Becky: No, she hasn't eaten yet. She... did you assess her lungs?

Mia: Yeah, she had wheezing in her lungs last time I checked, which was about an hour ago and yeah...

Michelle: Okay great. Alright great, thank you for the information guys. 
During this conversation, the outgoing group is seen elaborating on their charting to call attention to aspects of the patient's condition that will be relevant for incoming nurses. This entails a different kind of body work as students physically gesture, point, and engage with the board, movements that will not translate to a clinical space where students will likely work with an electronic medical record instead. In addition, the outgoing group emphasizes specific physical phenomenon that incoming nurses should be aware of like the leaking of urine into a newly changed wound dressing. They also emphasize emotional body work by highlighting a sense of the patient's well being: "how conscious she is and stuff... make sure she's good." In this way, they shape the body work of the incoming nurses, alerting them to embodied patient knowledge that they will want to acquire during their shift.

At the same time, as the incoming nurses take in the team's documentation they are considering its implications for their own care. Michelle's question about blood pressure is a clear indication of this thought process in action. Michelle is already anticipating her embodied patient interactions, drawing on an intuition about patient needs that occurs even prior to physical or verbal interaction (AUTHOR 2019). Her question calls attention to an aspect of patient care that the previous group has failed to account for in their charting and explicitly identifies a gap in their body work.

When miscommunications happened in simulations, the patient chart could also become a site where misinterpretations in body work were carried across groups. For example, during a pediatric simulation one group asked about infant Eric's skin. Maura responded that it was "warm and moist," intending to indicate that it was normal. However, the students misinterpreted this response to mean that the baby was sweating. This was an instance where the artificiality of the simulation context interrupted students from having an embodied interaction with the patient that would have provided 
them with the physical sense that he was healthy. These students later determined that his blanket felt wet as well and during a phone call to the physician described Eric as "sweating profusely." On the board, under "Skin" they wrote "Warm/Moist," and also listed under "Plan," "Keep pt dry and comfortable." During the debrief, their instructor clarified that the baby was not, in fact, sweating but his blanket was just moist from coughing up formula. The debrief provided students and instructors an opportunity to both recognize those misinterpretations and also become aware of the processes by which body work knowledge could become crystallized into the patient's record. In this way, the body work of an individual nurse moves from being an isolated sensory experience to shared patient knowledge.

\section{Implications for Technical Writing Pedagogy}

Earlier, I pointed out that educational training spaces can be productive sites for studying body work precisely because physical and emotional workplace interactions are not yet normalized. While my findings section showed how the theory of rhetorical body work can inform nursing education and practice, this section considers parallel educational tasks in technical writing pedagogy (simulated assignments). Overall, I argue that the theory of rhetorical body work can inform our approach to preparing students for deeply embodied rhetorical tasks in our courses.

Many technical communication teachers use simulation-based assignments that ask students to write outside of the role of college student and to an audience beyond college professor. Writing tasks like these help encourage rhetorical flexibility and cue transfer of writing knowledge (Brent, 2011). Thus, just as nursing students are being asked to embody their future professional role and perform emotions for a particular patient, our technical writing students are often asked to take on a range of identities 
and perform for a variety of audiences. However, instructors have paid little attention to the bodily implications of these tasks.

In their discussion of embodiment in the writing classroom - and specifically the pain that emerges from extended writing practice - Owens and Ittersum (2013) discuss the paucity of attention to physical experiences in educational spaces. They argue: "students truly had no framework for understanding the potential value of bodily learning in a writing class" (p. 96). Bringing the concept of rhetorical body work and insights from this analysis to these tasks can help to enrich their framing and execution. Simulation-based technical writing can be strengthened by asking students to both embody the position of their imagined author and to move beyond stereotypes in understanding the needs of their audience.

\section{Embodying Authorship}

In my research, students had the advantage of participating in hospital placements alongside simulations, giving them opportunities to observe both nurses in practice and a range of real-life patients. My focal students frequently referenced clinical experiences while explaining their choices during a simulation and their understanding of the nursing role. Perhaps most important, then, is the recognition that asking students to embody a new identity for a writing assignment is neither a simplistic nor a purely discursive task. We are asking for physical and emotional performances that require intimate knowledge of an other to be delivered with compassion and authenticity. Several authors have offered possible directions for helping support students' embodied access to various author positionalities.

If students are being asked to write from their own perspective, instructors can encourage them to delve deeply into their own positionality and experience. This might include accounting for the social positions they embody on a daily basis. For example, 
Godbee et al. (2015) describe using a "Social Identity Wheel," which asks students to identify factors like race and language background and to list out "what others see first" about them. Instructors might also ask a class to articulate their physical experiences with a text or technology. Swacha (2018) describes the creation of embodiment maps that "visually portray how [students] use a certain text physically" (p. 272). She explains how this enables students to compare and contrast embodied experiences to gain an awareness of physical variation and "how the text represents certain ideologies" (p. 272).

In contrast, if an assignment asks students to take on the role of an other, especially a future self, we should provide opportunities for students to explore that positionality deeply before it is adopted. Authors in writing studies have advocated for performances of audience that are tied to texts that represent a particular worldview. Fleckenstein (2009) describes a process of "shadowing" where students choose a line or phrase from a text and free write about it, expanding on its perspective and exploring the identity deeply (p. 99). Meanwhile, Micciche (2007) recommends physically embodying an author's emotions to better empathize with their worldview. To move our students closer to these positions, instructors should consider spaces where they could access this perspective, like informal interviews, observations, or online forums. Overall, instructors should critically reflect on the preparation we have done to provide the space, time, and resources necessary for these performances. In what ways have we helped students to bridge the gap between their own experiences and those of their imagined author? How long have we devoted to understanding this new position before expecting a performance in the form of a draft? What kinds of feedback can we, other students, or those outside the class offer on this performance? 


\section{Humanizing Audience}

Rhetors have been relying on broad-stroke stereotypes to define their imagined audience since the days of Aristotle's taxonomy of audience emotions. Rose \& Tenenberg (2018) provide an updated analysis of these driving stereotypes in their recent discussion of personas in technical communication. Personas, much like the patient profiles nursing students receive in simulations, "include images suggestive of prototypical users, bullet lists of user characteristics (often drawn from research), and/or short biographical narratives" (p. 162). The authors argue that in their design and animation, personas reveal as much about their creators as they do about potential users; their assumptions, strengths, and limitations are all embodied in the guise of an imagined audience. In similar ways, when we ask students to write for an imagined reader, we run the risk of revealing the shortcomings of their particular positionalities. The question then becomes, how do we aid students in developing an "embodied literacy" that will account for "how users interact with technologies and texts in varied physical, material ways"? (Swacha, 2018, p. 261).

My focal students' thoughts on the sources and interruptions of empathy for their patients can provide some insight. Many of them noted that activities that were created specifically to foster empathy with patient experience frequently fell flat. For example, in one instance they wore a weighted suit and vision-distorting glasses in order to simulate the experience of an elderly person in the world. In contrast, they described a great deal of empathy for the patient they were caring for in the simulation. My focal student Michelle's response was indicative:

I mean I was just kind of thinking about how would I want to be treated if I'm in that position [...] I would want the nurses to be communicating with me, letting me know what's going on. If they go and huddle in the corner to talk about what they're going to do, I'd want to know what they're talking about [...] And that's 
kind of the same practice that we try to implement in our clinicals too is just to maintain that sense of empathy and caring, even if we're not wearing a weighted suit. So having that empathy, you know.

What Michelle's response indicates is that students' empathy developed not out of embodying the experiences of the patient but in seeing very tangibly how their actions impacted a simulated patient - having direct access to embodied audience response.

This reflection points to the importance of moving audiences out of our student's minds and into more concrete existence. This might happen through external campus partnerships, like Swacha's (2018) collaboration with a food pantry to design cookbooks for the elderly. Or it might happen through interdisciplinary collaborations, like Clark and Fischbach's (2008) activity in which students in a health writing class "role-play the presentation of their written grant proposal before a committee of professional public health education peers" (p. 15). Here, the authors leverage students' different disciplinary positions to provide more authentic feedback. Thus, in technical writing classes that bring together a variety of majors and backgrounds, we can do more to take advantage of the different perspectives that are already available to our students.

These are risky calls — asking students to perform another's perspective or relate to an other can easily turn into an inauthentic appropriation or a comedic endeavor, as demonstrated by the second exchange between Alice and Jason. However, it is important to recognize that students are often being asked to make these moves in technical writing courses without any recognition of the complexity of the task or its embodied implications. Instead, technical writing instructors should be strategic about the roles we ask students to take on in assignments and consider how physical and emotional performances might better prepare them for those roles. Research being done on Pedagogy and Theater of the Oppressed has a wealth of resources for designing role 
playing that explicitly addresses power relationships and incorporates embodiment (Godbee, Ozias, \& Kar Tang, 2015). Key questions for instructors should include:

- Are these roles representing perspectives our students will have had access to and be able to envision and understand? What kinds of resources have we provided to support their understanding of these perspectives?

- What are the power dynamics of these different positions? What kinds of stereotypes might be amplified and what would be the consequences of that amplification?

- How have we built in opportunities for students to critically reflect on their performances? How will problematic exchanges be addressed by instructors and other students?

My research demonstrates that body work is at forefront of these questions because students are learning to physically move and modulate their emotions for others.

Overall, my analysis points to the vital role of instructors in shaping students' body work. Maura was a fundamental part of the simulation's success, not just in facilitating action but also in cuing students' connection making to the professional world and calling their attention to the multiplicity of possibilities for action. As I demonstrated, she was often as physically and emotionally immersed in the simulation as her students and that level of engagement brought both authenticity and stakes to students' performances. The success of Maura's facilitation points to the many ways that technical writing instructors can create an environment in which students are able to position themselves in new rhetorical contexts and practice the physical, emotional, and discursive learning that will accompany their future roles. 
References

Booher, A. \& J. Jung (2018). "Situating feminist rhetorical science studies." Feminist rhetorical science studies: Human bodies, posthuman worlds. Edited by A. Booher \& J. Jung. Carbondale, IL: Southern Illinois University Press.

Brent, D. (2011). Transfer, transformation, and rhetorical knowledge: Insights from transfer theory. Journal of Business and Technical Communication, 25(4), 396420.

Britt, E. C. (2018). Reimagining advocacy: Rhetorical education in the legal clinic. State College, PA: Penn State Press.

Brittenham, R. (2017). The interference narrative and the real value of student work. College Composition and Communication, 68(3), 526.

Brown, P. R., Alaszewski, A., Swift, T., \& Nordin, A. (2011). Actions speak louder than words: the embodiment of trust by healthcare professionals in gynaeoncology. Sociology of Health \& Illness, 33(2), 280-295.

Clark, I. L., \& Fischbach, R. (2008). Writing and learning in the health sciences: Rhetoric, identity, genre, and performance. The WAC Journal, 19, 15-28.

Fisher, M. J. (2009). 'Being a chameleon': Labour processes of male nurses performing bodywork. Journal of Advanced Nursing, 65(12), 2668-2677.

Fleckenstein, K. S. (2009). Vision, rhetoric, and social action in the composition classroom. Carbondale, IL: Southern Illinois University Press.

Fountain, T. K. (2014). Rhetoric in the flesh: Trained vision, technical expertise, and the gross anatomy lab. New York: Routledge.

Gimlin, D. (2007). What is 'body work'? A review of the literature. Sociology Compass, 1(1), 353-370.

Godbee, B., Ozias, M., \& Tang, J. K. (2015). Body+ power+ justice: Movement-based workshops for critical tutor education. The Writing Center Journal, 61-112.

Gold, D., \& Enoch, J. (Eds.). (2019). Women at Work: Rhetorics of Gender and Labor. Pittsburgh, PA: University of Pittsburgh Press.

Hallenbeck, S., \& Smith, M. (2015). Mapping topoi in the rhetorical gendering of work. Peitho, 17(2), 200-204.

Harris, A. (2011). In a moment of mismatch: Overseas doctors' adjustments in new hospital environments. Sociology of Health \& Illness, 33(2), 308-320. 
"Health care employment projections, 2016-2026: An analysis of Bureau of Labor statistics projections by setting and by occupation." Center for Health Workforce Studies, University at Albany, 2018. <http://www.chws.albany.edu>.

Hochschild, Arlie. (1983). The Managed Heart: Commercialization of Human Feeling. Berkeley, CA: University of California Press.

Karwowski, W. (2012). The discipline of human factors and ergonomics. Handbook of Human Factors and Ergonomics. G. Salvendy (Ed.). John Wiley \& Sons, 3-37.

Knoblauch, A. A. (2012). Bodies of knowledge: Definitions, delineations, and implications of embodied writing in the academy. Composition Studies, 40(2).

LeMesurier, J. L. (2016). Mobile bodies: Triggering bodily uptake through movement. College Composition and Communication, 68(2), 292-316.

Lu, M. Z., \& Horner, B. (2009). Composing in a global-local context: Careers, mobility, skills. College English, 72(2), 113-133.

Magelssen, S. (2014). Simming: Participatory performance and the making of meaning. University of Michigan Press.

Micciche, L. R. (2007). Doing emotion: Rhetoric, writing, teaching. Boynton/Cook.

Mulla, S. (2014). The violence of care: Rape victims, forensic nurses, and sexual assault intervention. New York, NY: NYU Press.

Opel, D. S., \& Hart-Davidson, W. (2019). The Primary Care Clinic as Writing Space. Written Communication, 36(3), 348-378.

Owens, K. H., \& Van Ittersum, D. (2013). Writing with (out) pain: Computing injuries and the role of the body in writing activity. Computers and Composition, 30(2), 87-100.

Rose, E. J., \& Tenenberg, J. (2018). Poor poor dumb mouths, and bid them speak for me: Theorizing the use of personas in practice. Technical Communication Quarterly, 27(2), 161-174.

Shakespeare, P. (2003). Nurses' bodywork: Is there a body of work?. Nursing Inquiry, 10(1), 47-56.

Shilling, C. (2011). Afterword: Body work and the sociological tradition. Sociology of Health \& Illness, 33(2), 162-166.

Singer, B. (2013). The Human Simulation Lab-Dissecting sex in the Simulator Lab: The clinical lacuna of transsexed embodiment. Journal of Medical Humanities, 34(2), 249-254. 
Swacha, K. Y. (2018). "Bridging the Gap between Food Pantries and the Kitchen Table": Teaching Embodied Literacy in the Technical Communication Classroom. Technical Communication Quarterly, 27(3), 261-282.

Van Dongen, E., \& Elema, R. (2001). The art of touching: The culture of 'body work' in nursing. Anthropology \& Medicine, 8(2-3), 149-162.

Wainwright, E., Marandet, E., Smith, F., \& Rizvi, S. (2010). The microgeographies of learning bodies and emotions in the 'classroom-salon'. Emotion, Space and Society, 3(2), 80-89.

Wolkowitz, C. (2002). The social relations of body work. Work, Employment and Society, 16(3), 497-510.

Wolkowitz, C. (2006). Bodies at work. Thousand Oaks, CA: Sage Publications. 
Figure Captions

Figure 1. Layout of the Adult Simulation Suite. Video screenshot by author.

Figure 2. Sean investigates Jason's itching skin. Video screenshot by author.

Figure 3. Student charting of elderly patient. Circles added. Photo by author. 